\title{
The Spectrum of Anti-MOG Associated Demyelinating Diseases in Children: A Review Illustrated with Clinical Cases
}

\section{Espectro de Doenças Desmielinizantes Associadas aos Anticorpos Anti-MOG em Idades Pediátricas: Revisão llustrada com Casos}

\author{
Duarte Armindo $\mathrm{R}^{1, *}$; Healion $\mathrm{E}^{2}$; Palavra $\mathrm{F}^{3,4,5}$ \\ 1-https://orcid.org/0000-0003-0001-742X / Neurorradiology Department / Hospital Beatriz Ângelo, Loures, Portugal. \\ 2-Faculty of Medicine, University of Coimbra, Coimbra, Portugal. \\ 3-https://orcid.org/0000-0002-2165-130X / Centre for Child Development, Neuropediatrics Unit / Centro Hospitalar e Universitário de \\ Coimbra, Coimbra, Portugal. \\ 4-University of Coimbra, Coimbra Institute for Clinical and Biomedical Research (iCBR), Faculty of Medicine, Coimbra, Portugal. \\ 5-Clinical Academic Center of Coimbra (CACC), Coimbra, Portugal.
}

Resumo

Introdução: Os autoanticorpos contra a glicoproteína da mielina do oligodendrócito (anti-MOG) estão associados a um largo espectro de doenças desmielinizantes do sistema nervoso central (SNC), sobretudo em idades pediátricas.

Este artigo tem com principal objetivo sumarizar os mais recentes dados publicados sobre o espectro de doenças desmielinizantes associadas a anti-MOG em crianças, integrando casos com documentada seropositividade para anti-MOG diagnosticados num centro terciário em Portugal.

Métodos: Foi realizada uma revisão dos artigos publicados em inglês durante o período 2008-2018, ilustrada com casos clínicos da nossa prática.

Resultados: Foram incluídos e analisados quarenta e oito artigos. Os anticorpos anti-MOG estão associados a um início precoce da doença e as crianças com doenças desmielinizantes do SNC apresentam títulos mais altos que os adultos com as mesmas entidades, reforçando o facto de estes anticorpos poderem ter um papel específico nos eventos desmielinizantes em idades pediátricas. Quatro casos clínicos ilustram este espectro clínico.

Conclusão: Os anticorpos anti-MOG estão associados a um espectro clínico muito heterogéneo, sendo evidente a sua relação com doenças desmielinizantes do SNC em idades pediátricas. Ainda não é possível definir um fenótipo clínico comum. O conhecimento aprofundado destas entidades nosológicas e sua fisiopatologia é fundamental para o correto diagnóstico e acompanhamento destes doentes.

\section{Abstract}

Introduction: Antibodies against myelin oligodendrocyte glycoprotein (antiMOG) are associated with a wide spectrum of demyelinating diseases of the central nervous system, particularly in pediatric patients.

This article aims to summarize the most recent literature about the spectrum of anti-MOG-associated diseases in children, integrating cases with documented seropositivity for anti-MOG antibodies diagnosed at a tertiary center in Portugal.

Methods: A review of articles written in English and published during the 20082018 period was conducted and illustrated with clinical cases from our practice.

Results: Forty-eight papers were included and reviewed. Anti-MOG antibodies are associated with an earlier age at disease onset and children with acquired demyelinating syndromes have higher titers of these antibodies when compared with
Informações/Informations: Artigo de Revisão, publicado em Sinapse, Volume 20, Número 1, janeiro-março 2020. Versão eletrónica em www. sinapse.pt

Review Article, published in

Sinapse, Volume 20, Number

$1-2$, january-march · april-june 2020. Electronic version in

www.sinapse.pt

(C) Autor (es) (ou seu (s) empregador (es)) 2020.

Reutilização permitida de acordo com CC BY-NC.

Nenhuma reutilização

comercial.

(C) Author(s) (or their employer(s)) 2020. Re-use permitted under CC BY-NC. No commercial re-use.

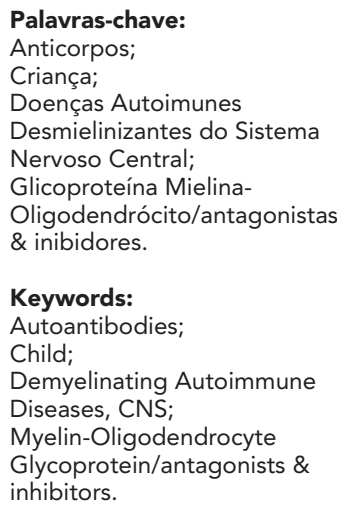

Keywords:

Autoantibodies:

Child;

Demyelinating Autoimmune Diseases, CNS

Myelin-Oligodendrocyte

Glycoprotein/antagonists \& inhibitors.

\footnotetext{
*Autor Correspondente / Corresponding Author: Rui Duarte Armindo Avenida Carlos Teixeira 3 2674-514 Loures, Portugal ruimigueldarmindo@gmail.com

Recebido / Received: 2020-01-19 Aceite / Accepted: 2020-02-23
}

Publicado / Published: 2020-06-30

DOI: $10.46531 /$ sinapse/ AR/200002/2020 
adults with the same diseases, highlighting the fact that anti-MOG antibodies may have a particular role in demyelinating events in children. Four clinical cases illustrate the disease spectrum.

Conclusion: Anti-MOG antibodies are associated with a very heterogeneous clinical spectrum, with an evident relation with acquired demyelinating syndromes in children. It is not yet possible to delineate a common clinical phenotype. Clinical awareness and knowledge of the pathophysiology of these entities can be crucial for correct diagnosis and management of these patients.

\section{Introduction}

Myelin oligodendrocyte glycoprotein (MOG) is a glycoprotein exclusively expressed in the central nervous system (CNS) and its location in myelin outermost surface and membrane of oligodendrocytes makes it a potential target for autoimmune phenomena.' Autoantibodies against MOG may represent important diagnostic and prognostic biomarkers as anti-aquaporin-4 (anti-AQP4) in neuromyelitis optica (NMO) and neuromyelitis optica spectrum diseases (NMOSD) has been since its identification in the early 2000 s. $^{2}$

Anti-MOG antibodies can be associated with a large spectrum of acquired demyelinating diseases, predominantly in pediatric ages. Using cell-based assays (CBA), anti-MOG antibodies have been identified in children with acute disseminated encephalomyelitis (ADEM), optic neuritis (ON), NMO/NMOSD and transverse myelitis (TM) but rarely in patients with multiple sclerosis (MS) or older ages. ${ }^{3,4}$

The mechanism through which anti-MOG antibodies are pathogenic is not yet fully understood, precluding their consideration as biomarkers so far in specific diagnostic criteria. ${ }^{5}$

\section{Methods}

This review is based on data collected from articles published in the PubMed platform over the 2008-2018 period, focusing on anti-MOG antibodies and the spectrum of associated diseases in children and adolescents (age under 18 years old). The keywords used for article selection were "anti-MOG", "spectrum", "acquired demyelinating syndromes", "pediatric" and "children"; alone and in combination. All articles identified were written in English and only items for which the full text was available were considered. A total of 46 articles were included in this review.

After defining the spectrum of CNS conditions asso- ciated with anti-MOG antibodies, we illustrate it with clinical cases from our institution, a tertiary center for Neuropediatrics in Portugal.

\section{Pathophysiological Background \\ I - The target protein}

MOG belongs to the immunoglobulin superfamily and the full-length protein is composed of 218 amino acids. It is exclusively expressed on the outermost lamellae of the myelin sheath and on the surface of oligodendrocytes in CNS. MOG represents less than $0.05 \%$ of myelin proteins but plays an important role as a surface biomarker of oligodendrocyte maturation. It is also relevant for myelin integrity, adhesion and cell surface interactions. Its location in the external surface of the myelin sheath makes it a putative target for autoimmune mechanisms that result in CNS inflammation and demyelination. ${ }^{4-8}$

MOG was identified for the first time 30 years ago, in an animal model of multiple sclerosis (MS) which showed that antibodies against MOG can increase demyelination, inducing both cell-mediated cytotoxicity and humoral immune response. However, the pathophysiological mechanisms mediated by these antibodies remain not totally clear. ${ }^{8,9}$

\section{2 - Antibody detection}

There are different types of anti-MOG antibodies, but only those against conformational epitopes on the extracellular domain seem to be pathogenic. When using animal models, it is important to consider that the predicted sequence of the mature MOG protein is conserved among mammalian species, but certain epitopes are length or species-dependent, which means that applicability to humans needs to be carefully evaluated. ${ }^{10}$ With the development of CBA, the majority of studies confirmed that both prevalence and titers of anti-MOG antibodies are higher in children with CNS demyelina- 
tion than in adults. Higher antibody titers are consistently associated with younger age at disease onset. ${ }^{1,12}$ In studies using CBA, anti-MOG antibodies were rarely found on healthy controls or in patients with other inflammatory neurological diseases, like viral encephalitis, neither on systemic immune diseases, such as type I diabetes mellitus, suggesting that anti-MOG antibodies are specific for CNS demyelination. ${ }^{7,9,13-15}$

\section{3 - Anti-MOG immunopathogenesis}

There is growing evidence that B cells and antibodies have a central role in inflammatory and demyelinating events in the CNS. ${ }^{9,16}$ It is not yet known if anti-MOG antibodies have an active role in demyelinating diseases or if their presence is an epiphenomenon secondary to myelin destruction and antigen spreading. ${ }^{5}$ First studies using animal models argue in favor of a secondary immune reaction such as an antibody-dependent cell-mediated cytotoxicity. ' One study has shown that MOG IgG from pediatric patients can induce natural killer (NK) cells, causing the death of cells expressing MOG. The same study also evidenced that there is a correlation between antibody titers and the extension of antibody-dependent cell-mediated cytotoxicity, leading to the assumption that higher titers are associated with higher levels of cytotoxicity. 5,9

Anti-MOG antibodies are mainly produced peripherally, their detection is more sensitive in the serum than in the cerebrospinal fluid (CSF) and no association with intrathecal oligoclonal bands has been established. To be pathogenic in humans, anti-MOG antibodies probably need to pass through the blood-brain barrier (BBB). The most reasonable hypothesis suggests that reactive $T$ cells activated during infections damage the BBB, allowing pathogenic antibodies to access the CNS. Another possible theory is that direct infection of the brain parenchyma exposes CNS antigens to the immune system, affecting BBB and triggering autoimmunity. ${ }^{5,17}$

The majority of anti-MOG antibodies are able to fix complement and bind Fc receptors (lgG I isotype). There is emerging evidence that complement component $\mathrm{C} 5 \mathrm{a}$ is involved in Fc receptor regulation and sensing. Fc receptor (FcR) and complement interact with each other at the level of $\mathrm{C} 5 \mathrm{a}$ at sites of inflammation. ${ }^{18,19}$

Recent research on the cytokines profile in anti-MOG positive patients verified that B cell-related cytokines in CSF were significantly higher in these subjects. Specifically, CXCLI3 is increased in anti-MOG positive pa- tients. This cytokine facilitates ThI7 cell migration into the CNS. In turn, ThI7-related cytokines, such as IL-6, correlate with monophasic acquired demyelination syndromes, working as critical switch factors to activate naive $\mathrm{T}$ cells towards pro-inflammatory ThI 7 lymphocytes. In addition, granulocyte colony-stimulating factor (G-CSF) is also induced by Th 7 cells and stimulates survival, proliferation and differentiation of neutrophils. ${ }^{20}$

The histopathology associated with anti-MOG antibodies shows demyelinating lesions with features of MS pattern II, highlighting their strong inflammatory burden, with well-demarcated confluent plaques, macrophages containing myelin debris and evidence of complement cytotoxicity. I Anti-MOG antibodies cause disruption of the oligodendrocyte cytoskeleton with loss of organization of the thin filaments and of the architecture of microtubules. ${ }^{21,22}$

\section{The Clinical Spectrum}

\section{I - Acquired demyelinating syndromes in children and anti-MOG antibodies}

Acquired demyelinating syndromes (ADS) in children are complex diseases resulting from an interaction between a genetic susceptibility profile and environmental risk factors of multiple natures. Previous studies reported nationwide ADS incidences of $0.6-0.9 / 100000$ children. ${ }^{23,24}$ The clinical spectrum is very heterogeneous, comprising MS, ADEM, NMO/NMOSD, ON, TM and clinically isolated syndrome $(\mathrm{CIS}) .^{12} \mathrm{MS}$, idiopathic $\mathrm{ON}$ and $\mathrm{ADEM}$ represent the most common inflammatory and demyelinating diseases of the CNS among all ages. Demyelinating diseases are considered an important cause of neurological disability in children and young adults. The establishment of their relationship with anti-MOG antibodies may be of relevance to identify specific forms of these diseases, with potentially different treatment and prognosis. ${ }^{8}$

\section{I.I - Acute disseminated encephalomyelitis}

ADEM is a well-characterized demyelinating syndrome defined by multifocal involvement of CNS and encephalopathy. Brain magnetic resonance imaging (MRI) typically shows diffuse and poorly demarcated, bilateral lesions involving most predominantly the cerebral white matter and the spinal cord. This entity affects mainly children and young adults. It is typically preceded by exposure to infectious agents. ${ }^{25-27}$

ADEM has usually a monophasic presentation, especially if early diagnosed and adequately treated, pro- 
viding a favorable prognosis. Anti-MOG antibodies are present in approximately $50 \%$ of children with ADEM, making it the most frequent syndrome associated with anti-MOG seropositivity. Patients usually have very high titers of these antibodies at presentation. ${ }^{27}$

A subgroup of children with ADEM develops a relapsing disease course, often leading to a diagnosis of MS or NMOSD. More recently, a distinct phenotype has been described, with patients presenting ADEM followed by single or recurrent episodes of ON.,17,28,29 The majority of children with ADEM followed by ON (ADEM-ON) are positive for anti-MOG antibodies. ADEM-ON could be the final diagnosis in up to $40 \%$ of anti-MOG positive patients who initially presented with ADEM. Episodes of $\mathrm{ON}$ in this context are usually severe and very disabling. ${ }^{28}$

\section{I.2 - Optic neuritis}

$\mathrm{ON}$ is characterized by oculodynia aggravated with eye movement and visual loss and is a common manifestation of MS or NMOSD. ${ }^{30,31}$ Recent data suggest that anti-MOG antibodies are present in certain forms of ON. There is a strong association between anti-MOG antibodies and simultaneous bilateral and/or recurrent ON among all ages. ${ }^{31}$

ON imaging frequently shows bilateral and extensive involvement of the optic nerves, affecting mostly the anterior visual pathway. ${ }^{31}$ The entity defined as recurrent ON (RON) is typically corticosteroid-responsive, often requiring systemic immunosuppression for a steroidsparing effect. ${ }^{30,31}$

$\mathrm{ON}$ is the second most prevalent demyelinating manifestation associated with anti-MOG antibodies. Patients usually have a relapsing disease course and it seems reasonable to suggest early secondary prevention strategies, such as corticosteroid maintenance, intravenous immunoglobulin (IVlg) or chronic immunosuppression with mycophenolate mofetil or rituximab. ${ }^{32}$

\section{I.3 - Transverse myelitis}

TM is caused by inflammation of the spinal cord and it is characterized by motor, sensory and/or autonomic dysfunction with acute onset. The diagnosis of isolated myelitis is rare in children, more commonly being a manifestation of other ADS. The typical MRI appearance is of abnormal signal affecting more than two-thirds of the cross-sectional area of the cord extending for up to 3-4 spinal segments. Correct diagnosis and rapid initiation of treatment are fundamental to achieve a favorable prognosis. Treatment options include immunomodulatory therapy using intravenous corticosteroids or plasma exchange. ${ }^{33}$ There is little information about the association of TM with anti-MOG antibodies, but cases of longitudinally extensive TM (LETM) with marked grey matter involvement have recently been described in children with these antibodies. Additionally, anti-MOG associated myelitis frequently involves the lower cord, including the conus medullaris. ${ }^{34}$

\section{I.4 - Neuromyelitis optica and neuromyelitis optica spectrum disorders}

$\mathrm{NMO}$ is an autoimmune demyelinating disorder classically characterized by episodes of recurrent unilateral or bilateral ON and LETM. ${ }^{35}$ Additional diagnostic criteria include a brain MRI that does not match the criteria for MS and seropositivity for anti-AQP4 antibodies. ${ }^{19}$ Atypical forms of the disease are included in the designation of NMOSD, which comprises patients with single or recurrent events of LETM or recurrent or simultaneous bilateral $\mathrm{ON} .^{35}$

NMO pathogenesis is related to anti-AQP4 antibodies. ${ }^{36}$ AQP4 is a water channel protein essentially expressed by astrocytes and the antibody is a highly sensitive and specific biomarker for NMO.,37 Near $90 \%$ of patients with $\mathrm{NMO}$ and more than half of the patients with NMOSD are positive for anti-AQP4 antibodies, but a subgroup of patients (up to $12 \%-30 \%$ in some series) is seronegative for AQP4 antibodies. ${ }^{5}$ Recent studies revealed the presence of anti-MOG antibodies in patients seronegative for anti-AQP4. ${ }^{19,31,35-38}$

Anti-MOG positive patients frequently have a younger age at onset and a clinical phenotype of recurrent $\mathrm{ON}$ or LETM. There is also a strong association between anti-MOG antibodies and simultaneous bilateral $O N$ and lesions of the lower cord are significantly more common in anti-MOG than anti-AQP4 seropositive patients. In addition, anti-MOG positive patients frequently have a better prognosis. ${ }^{37-39}$

Recent data suggest that a minority of patients is positive for both anti-AQP4 and anti-MOG antibodies, presenting worse prognosis. ${ }^{30} \mathrm{MRI}$ imaging and optical coherence tomography (OCT) are indispensable for the diagnosis and evaluation of NMOSD, ${ }^{37}$ with recent works suggesting significantly higher macular damage on patients with anti-AQP4 antibodies than in those positive for anti-MOG. ${ }^{40}$ 


\section{I.5 - Multiple sclerosis}

MS is the most common demyelinating disease of the CNS among all age groups. It is relatively uncommon in childhood, representing near $5 \%$ of the total MS population. ${ }^{7,27}$ Anti-MOG antibodies are present in a small percentage of children with MS. Studies in MS patients did not use a very high titer for cut off, suggesting that anti-MOG antibodies are rare in MS and may even represent a negative biomarker for this condition. AntiMOG positive children with MS usually have different clinical phenotypes, presenting with more evident pleocytosis, rare intrathecal oligoclonal bands and atypical MRI lesions, confluent and asymmetrical., $4,17,26,29,41$

\section{Clinical Relevance}

It remains difficult to establish a straightforward clinical spectrum for anti-MOG related conditions, given the variety of the aforementioned phenotypes already associated with the presence of these antibodies. There seems to be a bimodal distribution of anti-MOG seropositive patients by age of onset, with a younger group (4-8 years old) having a high prevalence of ADEM and an older group (13-18 years old) having predominantly $\mathrm{ON} .^{16}$

Anti-MOG antibodies were found in around $\mathrm{I} / 3$ of children with ADS. There are no significant differences in patient gender, race or family history of autoimmune diseases. ${ }^{3,16}$ Recent studies found that a substantial proportion of anti-MOG positive patients have relapsing disease courses, normally associated with high persisting titers, ${ }^{35}$ discrediting earlier beliefs that invariably associated these antibodies with good prognosis and supporting the argument for antiMOG testing at disease onset and during follow-up. ${ }^{32,42-44}$

Some laboratory and imaging findings seem to be associated with anti-MOG seropositivity: peripheral leukocytosis, CSF pleocytosis and absent CSF oligoclonal bands, large $\mathrm{T} 2$ hyperintense lesions with cortical and deep grey matter involvement have been described. ${ }^{4,16}$ Some series and case reports highlighted frequent sparing of the corpus callosum and thoracic cord, but others found lesions with this topography in the anti-MOG positive group. ${ }^{16,43}$

Immunological and histopathological data can also help in the differentiation of anti-MOG associated demyelination from other ADS, by revealing primary demyelination of oligodendrocytes, antibody deposition and complement activation. ${ }^{45}$

These differences led researchers from different groups to propose that anti-MOG antibody-associated
CNS demyelination should be considered an independent disease entity. ${ }^{42-45}$

\section{Treatment and Outcomes}

Considering anti-MOG antibodies and their pathogenic potential, it seems reasonable to treat anti-MOG associated diseases with immunosuppressive agents, including corticosteroids, IVIg, plasma exchange or B-celldirected therapies, such as rituximab. Disease-modifying immunomodulatory therapy used for MS may have a detrimental impact on anti-MOG positive children. ${ }^{43,46}$

The efficacy of current treatment options is highly variable, ${ }^{4}$ but there is usually an initial response to steroids and plasma exchange. Steroid-sparing therapies such as azathioprine and mycophenolate mofetil could be very useful to avoid side effects but may take a longer time to reach total efficacy. ${ }^{42}$ Late-onset neutropenia after rituximab therapy (LONART), a rare but potentially life-threatening complication, has recently been reported in two patients under long-term rituximab therapy for anti-MOG associated conditions. ${ }^{47}$ Treatment failure rates are also more elevated on non-steroidal maintenance immunotherapy. ${ }^{28}$

Relapses should be acutely treated with high doses of steroids (intravenous methylprednisolone $1000 \mathrm{mg} /$ day or $30 \mathrm{mg} / \mathrm{kg} /$ day in children under $30 \mathrm{~kg}$, during 3-7 days), followed by low doses of oral prednisone or monthly IVIg, mycophenolate mofetil or rituximab. ${ }^{48}$

Anti-MOG antibodies serostatus (absence/presence and titers) should be used in conjunction with clinical information to guide maintenance therapy, but stronger recommendations are needed on this subject. ${ }^{28,32,37,45}$

\section{Case Reports}

\section{Case I - ADEM-ON}

An II-year-old boy was originally admitted with acute-onset encephalopathy, focal occipital seizures and sphincter dysfunction. Initial MRI showed diffuse, bilateral lesions involving most predominantly the cerebral white matter (Fig. I), compatible with the diagnosis of ADEM.

After a good clinical and radiological response to corticotherapy, during a follow-up period of 4 years, two episodes of right ON were registered (Fig. 2). During the second of these episodes, anti-MOG seropositivity was determined. Maintenance therapy with azathioprine has been effective. 


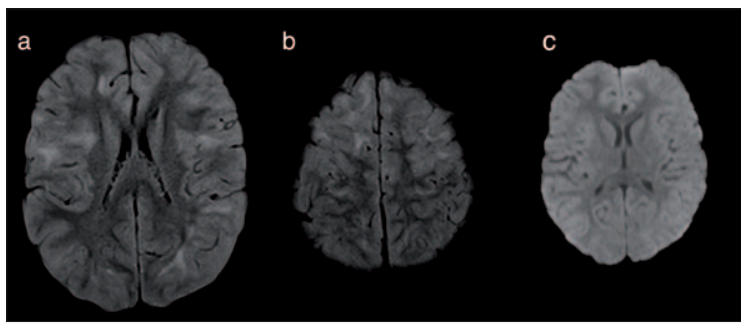

Figure 1. Brain MRI; axial fluid-attenuated inversion recovery (FLAIR) $(a, b)$ and diffusion-weighted imaging (DWI) (c) images showing diffuse foci of hyperintensity predominantly involving the subcortical white matter of both cerebral hemispheres, without evidence of restricted diffusion.

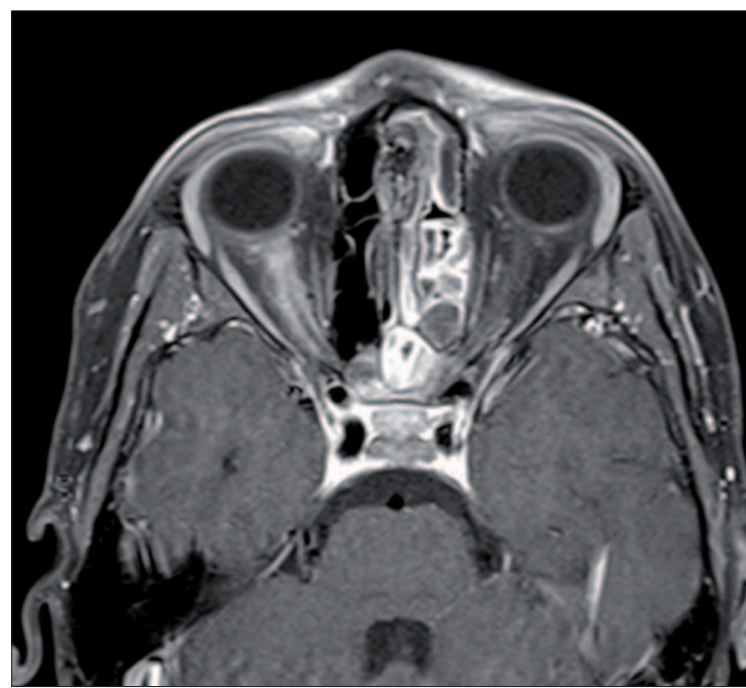

Figure 2. MRI of the orbits; axial post-contrast T1-weighted image of the orbits showing enhancement of the intra-orbital portion of the right optic nerve and optic nerve sheath compatible with optic neuritis.

\section{Case 2 - RON}

A 15-year-old male adolescent with history of right ON two years earlier (considered idiopathic at the time), was admitted with a similar clinical presentation and serum analysis was positive for anti-MOG antibodies. MRI showed typical signs of ON (Fig. 3), without evidence of other demyelinating lesions.

\section{Case 3 - TM}

A 14-year-old boy presented with subacute paraparesis with left-side predominance, sphincter dysfunction and loss of sensation in the lower half of the body. These symptoms had been preceded by an upper respiratory viral infection. Spinal MRI documented a lower cord transverse myelitis pattern, slightly asymmetric (Fig. 4), highly suggestive of anti-MOG involvement, even though first blood tests were negative for anti-MOG or anti-AQP4 antibodies (serum study was only performed after the beginning

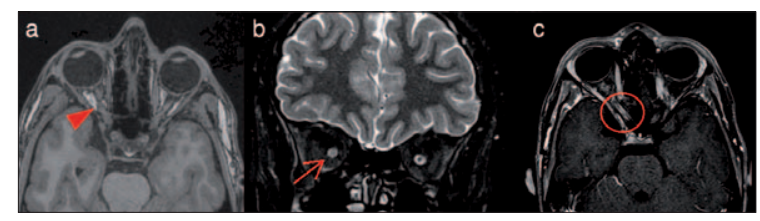

Figure 3. MRI of the orbits; axial T1-weighted (a), coronal T2-weighted (b) and axial post-contrast T1-weighted images showing swelling (red arrowhead), high T2 signal (red arrow) and contrast-enhancement (red circle) of the right optic nerve.

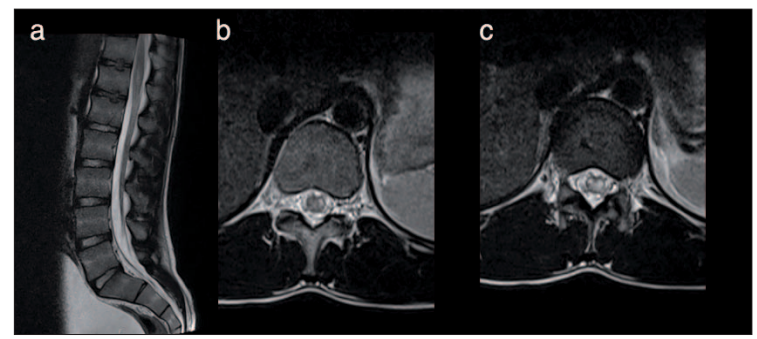

Figure 4. Spinal cord MRI; sagittal T2-weighted (a) and axial images at the level of T11 (b) and T12 (c) documenting a longitudinally extensive transverse myelitis of the lower segments of the spinal cord (and conus medullaris) characterized by parenchymal expansion and T2 hyperintensity with predominant grey matter involvement.

of corticosteroid treatment). There was good response of the motor symptoms and almost complete resolution of the MRI findings with 7 days of intravenous corticotherapy and there is no evidence of further demyelinating episodes over a follow-up period of around 6 months.

\section{Case 4 - NMOSD}

A 2-year-old girl presented with fever and marked drowsiness, without motor or other focal neurological deficits. Brain MRI showed multiple and bilateral supratentorial lesions, predominantly of the subcortical white matter, with foci of contrast enhancement (Fig. 5).

After an apparently good clinical response to corticosteroids, follow-up MRI 6 months later showed multiple de novo intracranial demyelinating lesions, some with radiological evidence of inflammatory activity and one with the typical aspect of NMOSD "arch bridge"

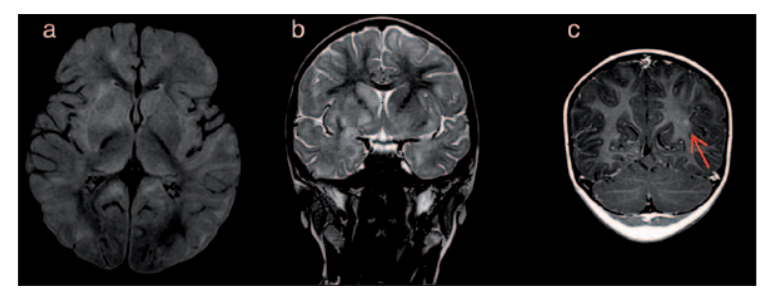

Figure 5. Brain MRl; axial FLAIR (a), coronal T2-weighted (b) and coronal post-contrast T1-weighted images evidencing multiple and bilateral cortical and subcortical T2/FLAIR hyperintense lesions, marked involvement of the right basal ganglia and some areas of patchy subcortical enhancement (red arrow). 
pattern (Fig. 6). Laboratory tests showed anti-MOG seropositivity. The diagnosis of anti-MOG associated NMOSD was considered probable and after treatment of the relapse with corticotherapy she was started on monthly IVlg. No further episodes or lesions were documented in a follow-up period over 2 years.

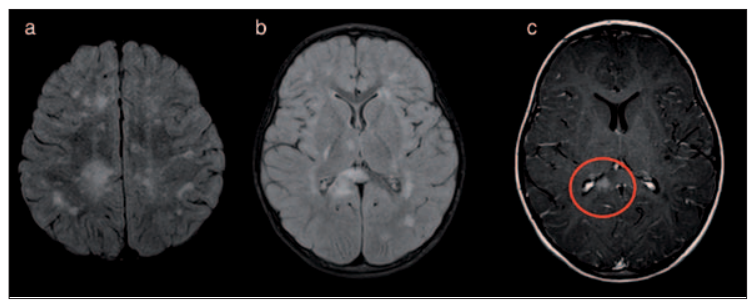

Figure 6. Brain MRI; axial FLAIR $(a, b)$ and post-contrast T1-weighted (c) images showing various de novo subcortical lesions, with a typical "arch bridge" callosal lesion with heterogeneous enhancement after contrast (red circle).

\section{Conclusion}

Anti-MOG antibodies are highly associated with ADS in children, representing a possible diagnostic and prognostic biomarker for the diagnosis of these demyelinating diseases in pediatric ages. Our cases are good examples of the diversity of phenotypes included in this spectrum, also illustrating some of the more common imaging findings and therapeutic options discussed. With growing knowledge of immunopathogenic mechanisms associated with antiMOG antibodies, large prospective, multi-center studies are now needed to assess the true clinical relevance and possible correlation titers with disease activity. ${ }^{44}$

\section{Responsabilidades Éticas}

Conflitos de Interesse: Os autores declaram a inexistência de conflitos de interesse na realização do presente trabalho.

Fontes de Financiamento: Não existiram fontes externas de financiamento para a realização deste artigo.

Confidencialidade dos Dados: Os autores declaram ter seguido os protocolos da sua instituição acerca da publicação dos dados de doentes.

Consentimento: Consentimento para publicação foi obtido.

Proveniência e Revisão por Pares: Não comissionado; revisão externa por pares.

\section{Ethical Disclosures}

Conflicts of Interest: The authors have no conflicts of interest to declare.

Financing Support: This work has not received any contribution, grant or scholarship.

Confidentiality of Data: The authors declare that they have followed the protocols of their work center on the publication of data from patients.

Patient Consent: Consent for publication was obtained.

Provenance and Peer Review: Not commissioned; externally peer reviewed.

\section{References / Referências}

1. Peschl $P$, Bradl $M$, Höftberger $R$, Berger $T$, Reindl $M$. Myelin oligodendrocyte glycoprotein: deciphering a target in inflammatory demyelinating diseases. Front Immunol. 2017;8:529. doi: 10.3389/fimmu.2017.00529.

2. Reindl M, Jarius S, Rostasy K, Berger T. Myelin oligodendrocyte glycoprotein antibodies. Curr Opin Neurol. 2017; 30:295-301. doi:10.1097/wco.0000000000000446.

3. Hennes E-M, Baumann M, Lechner C, Rostásy K. MOG spectrum disorders and role of MOG-antibodies in clinical practice. Neuropediatrics. 2017; 49:3-11. doi: 10.1055/s0037-1604404.

4. Thulasirajah S, Pohl D, Davila-Acosta J, Venkateswaran S. Myelin oligodendrocyte glycoprotein-associated pediatric central nervous system demyelination: clinical course, neuroimaging findings, and response to therapy. Neuropediatrics. 2016; 47:245-52. doi:10.1055/s-0036-1583184.

5. Ramanathan S, Dale RC, Brilot F. Anti-MOG antibody: The history, clinical phenotype, and pathogenicity of a serum biomarker for demyelination. Autoimmun Rev. 2016;15:30724. doi: 10.1016/j.autrev.2015.12.004.

6. Adoni T. Anti-MOG syndrome: a road to be paved. Arq NeuroPsiquiatria. 2017;75:685-6. doi:10.1590/0004-282x20170147.

7. Di Pauli F, Mader S, Rostasy K, Schanda K, Bajer-Kornek B, Ehling $\mathrm{R}$, et al. Temporal dynamics of anti-MOG antibodies in CNS demyelinating diseases. Clin Immunol. 2011; 138:247-54. doi:10.1016/j.clim.2010.11.013.

8. Reindl M, Di Pauli F, Rostasy K, Berger T. The spectrum of MOG autoantibody-associated demyelinating diseases. Nat Rev Neurol. 2013; 9:455-61.

9. Brilot F, Dale RC, Selter RC, Grummel V, Kalluri SR, Aslam $M$, et al. Antibodies to native myelin oligodendrocyte glycoprotein in children with inflammatory demyelinating central nervous system disease. Ann Neurol. 2009; 66:833-42. doi:10.1002/ana.21916.

10. Menge T, Lalive PH, von Budingen HC, Genain CP. Conformational epitopes of myelin oligodendrocyte glycoprotein are targets of potentially pathogenic antibody responses in multiple sclerosis. J Neuroinflammation. 2011;8:161. doi: 10.1186/1742-2094-8-161.

11. Nakashima I. Anti-MOG antibody associated diseases. Brain Nerve. 2017; 69:1331-6. doi:10.11477/mf.1416200912.

12. Ketelslegers IA, Van Pelt DE, Bryde $S$, Neuteboom RF, Catsman-Berrevoets CE, Hamann D, et al. Anti-MOG antibodies plead against MS diagnosis in an Acquired Demyelinating Syndromes cohort. Mult Scler. 2015;21:1513-20. doi: $10.1177 / 1352458514566666$.

13. Lalive PH, Menge T, Delarasse C, Della Gaspera B, PhamDinh D, Villoslada $P$, et al. Antibodies to native myelin oligodendrocyte glycoprotein are serologic markers of early inflammation in multiple sclerosis. Proc Natl Acad Sci U S A. $2006 ; 10: 2280-5$.

14. McLaughlin KA, Chitnis T, Newcombe J, Franz B, Kennedy $J$, McArdel S, et al. Age-dependent B cell autoimmunity to a myelin surface antigen in pediatric multiple sclerosis. $\mathrm{J} \mathrm{Im-}$ munol. 2009;183:4067-76. doi:10.4049/jimmunol.0801888.

15. O'Connor KC, McLaughlin KA, De Jager PL, Chitnis T, Bettelli $E, X u C$, et al. Self-antigen tetramers discriminate between myelin autoantibodies to native or denatured protein. Nat Med. 2007; 13:211-7. doi: 10.1038/nm1488.

16. Fernandez-Carbonell C, Vargas-Lowy D, Musallam A, Healy B, McLaughlin K, Wucherpfennig KW, et al. Clinical and MRI phenotype of children with MOG antibodies. Mult Scler J. 2016; 22:174-84. doi: 10.1177/1352458515587751.

17. Polat I, Yis U, Karaoglu P, Ayanoglu M, Ozturk T, Guleryuz $H$. et al. Myelin oligodendrocyte glycoprotein antibody persistency in a steroid-dependent ADEM case. Pediatrics. 2016;137. pii: e20151958. doi: 10.1542/peds.2015-1958.

18. Schmidt RE, Gessner JE. Fc receptors and their interaction with complement in autoimmunity. Immunol Lett. 2005; 100:56-67. doi:10.1016/j.imlet.2005.06.022.

19. Lechner C, Baumann M, Hennes EM, Schanda K, Marquard 
K, Karenfort M, et al. Antibodies to MOG and AOP4 in children with neuromyelitis optica and limited forms of the disease. J Neurol Neurosurg Psychiatry. 2016;87:897-905. doi: 10.1136/jnnp-2015-311743

20. Kothur K, Wienholt L, Tantsis EM, Earl J, Bandodkar S, Prelog $\mathrm{K}$, et al. B cell, Th17, and neutrophil related cerebrospinal fluid cytokine/chemokines are elevated in MOG antibody associated demyelination. PloS One. 2016; 11:e0149411. doi: 10.1371/journal.pone.0149411.

21. Berg CT, Khorooshi R, Asgari N, Owens T. Influence of type I IFN signaling on anti-MOG antibody-mediated demyelination. J Neuroinflammation. 2017; 14:127. doi:10.1186/ s12974-017-0899-1.

22. Dale RC, Tantsis EM, Merheb V, Kumaran RY, Sinmaz N, Pathmanandavel K, et al (2014) Antibodies to MOG have a demyelination phenotype and affect oligodendrocyte cytoskeleton. Neurol Neuroimmunol Neuroinflamm. 2014; 1:e12. doi:10.1212/nxi.0000000000000012.

23. Banwell B, Kennedy J, Sadovnick D, Arnold DL, Magalhaes $\mathrm{S}$, Wambera K, et al. Incidence of acquired demyelination of the CNS in Canadian children. Neurology. 2009; 72:232-9. doi:10.1212/01.wnl.0000339482.84392.bd.

24. De mol CL, Wong YYM, Van pelt ED, Ketelslegers IA, Bakker DP, Boon $\mathrm{M}$, et al.Incidence and outcome of acquired demyelinating syndromes in Dutch children: update of a nationwide and prospective study. J Neurol. 2018; 265:13109. doi: 10.1007/s00415-018-8835-6.

25. Mayer MC, Meinl E. Glycoproteins as targets of autoantibodies in CNS inflammation: MOG and more. J Neurol Neurosurg Psychiatry. 2016;87:897-905. doi: 10.1136/jnnp2015-311743.

26. Baumann M, Sahin K, Lechner C, Hennes EM, Schanda K, Mader S, et al. Clinical and neuroradiological differences of paediatric acute disseminating encephalomyelitis with and without antibodies to the myelin oligodendrocyte glycoprotein. J Neurol Neurosurg Psychiatry. 2015; 86:265-72. doi: 10.1136/jnnp-2014-308346

27. Höftberger R, Lassmann H. Inflammatory demyelinating diseases of the central nervous system. Handb Clin Neurol. 2017;145:263-83. doi: 10.1016/B978-0-12-802395-2.00019-5.

28. Wong $Y Y$, Hacohen $Y$, Armangue $T$, Wassmer $E$, Verhelst $H$, Hemingway $C$, et al. Paediatric acute disseminated encephalomyelitis followed by optic neuritis: disease course, treatment response and outcome. Eur J Neurol. 2018;25:782-6. doi: 10.1111/ene.13602.

29. Miyauchi A, Monden $Y$, Watanabe $M$, Sugie $H$, Morita $M$, Kezuka $T$, et al . Persistent presence of the anti-myelin oligodendrocyte glycoprotein autoantibody in a pediatric case of acute disseminated encephalomyelitis followed by optic neuritis. Neuropediatrics. 2014; 45:196-9. doi:10.1055/s-0034-1371179.

30. Chalmoukou K, Alexopoulos H, Akrivou S, Stathopoulos P, Reindl M, Dalakas MC. Anti-MOG antibodies are frequently associated with steroid-sensitive recurrent optic neuritis. Neurol Neuroimmunol Neuroinflamm. 2015; 2:e131. doi:10.1212/nxi.0000000000000131.

31. Ramanathan S, Prelog K, Barnes EH, Tantsis EM, Reddel SW, Henderson AP, et al. Radiological differentiation of optic neuritis with myelin oligodendrocyte glycoprotein antibodies, aquaporin-4 antibodies, and multiple sclerosis. Mult Scler J. 2016; 22:470- 82. doi: 10.1177/1352458515593406.

32. Ramanathan S, Mohammad S, Tantsis E, Nguyen TK, Merheb V, Fung VS, et al. Clinical course, therapeutic responses and outcomes in relapsing MOG antibody-associated demyelination. J Neurol Neurosurg Psychiatry. 2018; 89:12737. doi:10.1136/jnnp-2017-316880

33. Wolf VL, Lupo PJ, Lotze TE. Pediatric acute transverse myelitis overview and differential diagnosis. J Child Neurol. 2012; 27:1426-36. doi: 10.1177/0883073812452916.

34. Wang C, Narayan R, Greenberg B. Anti-myelin oligodendrocyte glycoprotein antibody associated with gray matter predominant transverse myelitis mimicking acute flac- cid myelitis: a presentation of two cases. Pediatr Neurol. 2018;86:42-5. doi: 10.1016/j.pediatrneurol.2018.06.003.

35. Sato DK, Callegaro D, Lana-Peixoto MA, Waters PJ, de Haidar Jorge FM, Takahashi T, et al. Distinction between MOG antibody-positive and AQP4 antibody-positive NMO spectrum disorders. Neurology. 2014; 82:474-81. doi:10.1212/ wnl.0000000000000101.

36. Zhou L, Huang Y, Li H, Fan J, Zhangbao J, Yu H, et al. MOGantibody associated demyelinating disease of the CNS: A clinical and pathological study in Chinese Han patients. J NeuroimmunoL. 2017; 305:19-28. doi: 10.1016/j.jneuroim.2017.01.007.

37. Yan Y, Li Y, Fu Y, Yang L, Su L, Shi K et al (2016) Autoantibody to MOG suggests two distinct clinical subtypes of NMOSD. Sci China Life Sci. 2016;59:1270-81.

38. Jasiak-Zatonska M, Kalinowska-Lyszczarz A, Michalak S, Kozubski W (2016) The immunology of neuromyelitis optica-current knowledge, clinical implications, controversies and future perspectives. Int J Mol Sci. 2016;17:273. doi: 10.3390/ijms17030273.

39. dos Passos GR, Oliveira LM, da Costa BK, Apostolos-Pereira SL, Callegaro D, Fujihara K, Sato DK, et al. MOG-lgG-associated optic neuritis, encephalitis, and myelitis: lessons learned from neuromyelitis optica spectrum disorder. Front Neurol. 2018;9:217. doi: 10.3389/fneur.2018.00217.

40. Pandit L, Mustafa S, Nakashima I, Takahashi T, Kaneko K. MOG-IgG-associated disease has a stereotypical clinical course, asymptomatic visual impairment and good treatment response. Mult Scler J Exp Transl Clin. 2018;4:2055217318787829. doi: $10.1177 / 2055217318787829$.

41. Probstel AK, Dornmair K, Bittner R, Sperl P, Jenne D, Magalhaes $S$, et al. Antibodies to MOG are transient in childhood acute disseminated encephalomyelitis. Neurology. 2011;77:580-8. doi: 10.1212/WNL.0b013e318228c0b1.

42. Mariotto $S$, Ferrari $S$, Monaco $S$, Benedetti MD, Schanda $K$, Alberti D, et al. Clinical spectrum and IgG subclass analysis of anti-myelin oligodendrocyte glycoprotein antibody-associated syndromes: a multicenter study. J Neurol. 2017;264:2420-30. doi: 10.1007/s00415-017-8635-4.

43. Konuskan B, Yildirim $M$, Gocmen R, Okur TD, Polat I,

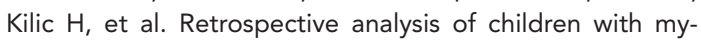
elin oligodendrocyte glycoprotein antibody-related disorders. Mult Scler Relat Disord. 2018;26:1-7. doi: 10.1016/j. msard.2018.07.022.

44. Di Pauli F, Reindl M, Berger T. New clinical implications of anti-myelin oligodendrocyte glycoprotein antibodies in children with CNS demyelinating diseases. Mult Scler Relat Disord. 2018;22:35-7. doi: 10.1016/j.msard.2018.02.023.

45. Weber MS, Derfuss T, Metz I, Brück W. Defining distinct features of anti-MOG antibody associated central nervous system demyelination. Ther Adv Neurol Disord. 2018;11:1756286418762083. doi: 10.1177/1756286418762083.

46. Hacohen $Y$, Wong $Y Y$, Lechner $C$, Jurynczyk $M$, Wright $S$, Konuskan $B$, et al. Disease course and treatment responses in children with relapsing myelin oligodendrocyte glycoprotein antibody-associated disease. JAMA Neurol. 2018;75:478-87. doi: 10.1001/jamaneurol.2017.4601.

47. Biotti D, Lerebours F, Bonneville F, Ciron J, Clanet M, Brassat D. Late-onset neutropenia and neurological relapse, during long-term rituximab therapy in myelin oligodendrocyte glycoprotein-antibody spectrum disorder. Mult Scler. 2018;24:1645-7. doi: 10.1177/1352458518765677.

48. Reindl M. Clinical course of MOG antibody-associated recurrent demyelinating diseases. J Neurol Neurosurg Psychiatry. 2018; 89:118. doi: 10.1136/jnnp-2017-317249. 